Received: 29.06.2014.

Professional article

UDK: 371.3:[378:73/76]

\title{
THEORETICAL AND PRACTICAL ASPECTS OF TEACHING METHODS FROM THE FACULTY OF FINE AND APPLIED ARTS
}

\author{
Goran Gavrić \\ European University - New Academy of Art, Belgrade \\ gavrik@sbb.rs
}

\begin{abstract}
In this paper, we try to at least partially answer the question of how Art Academies, namely the Faculty of Fine and Applied Arts, continuously improve teaching using well- prepared plan which identifies appropriate teaching methods. The specificity of lectures and exercises in these schools is reflected in theoretical and practical actions of their professors whose initial idea is to solve problems on the spot, therefore, during the process of making art. In that regard, it is very difficult to prepare in advance a lecture that will be fully realized according to the outlined plan. However, developing and constantly upgrading teaching methods after each lecture and exercise may aid in further research and improvement of methods of teaching at the Faculty of Fine and Applied Arts.

The aim of this paper is to provide some basic methods that are directly related to the interactive effect between professors and students. At the same time, these methods provide an opportunity to further develop teaching methods and the formation of the methodological framework of lectures and exercises. The result of this research is one of the possible methodological structures that in conjunction with here proposed teaching aids can be further developed and upgraded, all for the purpose of continuous improvement of teaching at the Faculty of Fine and Applied Arts.
\end{abstract}

Keywords: teaching methods, interactive methods, theory, practice, teaching aids

\section{Introduction}

Definition of teaching methods at the Faculty of Fine and Applied Arts presents an even bigger challenge, which is in this case the subject of art examined both through the practice and theory.

Inability to correctly set realistic parameters that will serve as a basis for exploring this issue at art academies, sets before us the task to determine precise and clear method for something that at first glance does not tolerate this kind of methodological limitation. For this reason doubts and ambiguities can arise eventhough the methods are completely clear. Therefore, our task is to (before even try to resolve the problem) define the method and then apply this new information joining certain issues define the method, and then apply this knowledge on further study of our methodological researh. Before all, however, we should explain the difference between research methods and research methodology.

The research method can be understood as all those methods used during the research. Therefore, the research method or technique refers to methods that lecturers at art academies use in conducting the methods of research. Therefore, all those methods that a lecturer uses during the course of his study are called the method of research. In the case that some methods can not be applied because there was also a change in the direction in which research is moving, the 
methods must either change or upgrade new elements that support and justify further research (Popper, 1973). We have some knowledge regarding certain methods, but on the other hand, we do not have a completely clear picture of the direction in which these methods could be developed and used later on. Therefore, changes in the course of the development of research in stages, require from lecturers at art academies to be seriously taken into consideration and adapted to each new situation. The lecturer will get closer to answer these pressing questions, as the original problem will be illuminated. It is impossible to describe the creative process, but the methods can be formulated. Cyclic repetition of certain methods during various historical periods occurs as the potentially variable phenomenon. It is only matter of time when the method will be changed or upgraded. In doing so, the connection method stems from unchanging structure of the system in which each successive method, if different from the previous one, is subjected to tests to determine its sustainability or unsustainability, and thus brought into a new relation with the methods that are repeated.

However, established definition of one method does not mean that we can apply that definition of the same method to different historical periods. For this reason, irregularities may occur because methods are developed outside the historical period in which they initially occured. However, the cyclical historical development can be, with time (which can take many years) balanced by neutralizing the differences that have arisen because of uneven and inconsistent development of some parts in relation to the whole. Nevertheless, irregularities in one particular period may be reviewed and transformed into regularities, but outside of that historical period, development of methods has very unpredictable course. Hermeneutical connection may contribute to a clearer and more realistic overview of the overall development of the art. It is necessary to explain how, why, when, and where the concepts of art, creativity, experience, genius, the world outside, inside, expression, style, symbol, etc., develope as part of the art. On the way of mastering different skills and encounters with unusual ideas that could lead to unexpected solutions, students are ready to move in multiple directions. But if we look at the student's progression by comparing it with the principle of hermeneutic circle's movement, we shall conclude that it may be incorrect, that is not moving in some common and prescribed direction, which is not the case with the hermeneutic circle. ${ }^{3}$

\section{Methodogical framework for the application of theory in teaching practice}

Art history and art itself is constantly metamorphosing. As social conditions change our views on the art of the past are changing too. The creative expressions of people who lived completely different lives for many years can still fascinate our minds and trigger our emotions. When we see a work of art from any period the first thing we ask ourselves is why it looks like that. The answer could be that the artist wanted the work to look like that. This may seem reasonable, but it eliminates the idea that the artist made a mistake or did not know enough to do anything else. Field of fine art presents the result of the artist's intents. However, if we established research methodology in this area (which is firmly based on clear methods), doubts regarding the process of making a work of art will be removed. Several approaches can help us solving this problem. First is the formal analysis which explains artist's desire to associate elements such as line and colour in a special way in order to present a specific subject content. According to second biographical approach, there is something in the artist's personality and individual spirit which

\footnotetext{
${ }^{3}$ For hermeneutic circle we can not say that it is irregular circle. This circcle is a logical operation which consists to assume a conclusion on the premises. Luis A. Schökel, A Manual of Hermeneutics, Academic Press, Sheffield, 1998, 73.
} 
leads to the creation of his work. Third approach is cultural, where artist expresses values . The fourth approach, which deals with customers and audience, explains that artist is authorized to produce work in a certain way, or that he represents a special idea.

Within artistic practice, methods of using results that are exactly reproduced, require practical engagement of technology and skills to control materials, thus theoretical engagement of science to establish regularities or causal connections within the general pattern of evidence. It is important to establish which theories of scientific method contribute to the development of artistic practice, and how to use them. Modern science developes an ability to solve problems using its fastidiousness and different types of phenomena reduction programs, thereby increasing the number of general theories. If the model is based only on the principle, without systematic practice which is necessary for it to be effectively involved in experimental science, the practice itself will not be effective. Only under the influence of free discussion science could extend its fully theoretical way of knowledge and logical methods.

Science could never find its necessary and close relationship with technology, measurement, and free experiment, if groups dealing with crafts and artistic skills do not exist. This source of science can lead to the assumption that the forms of production techniques and human labor in technical sense are parallel to the forms of positive way of thinking. However, the technology is not the latter application of theoretical, contemplative science represented by the truth, observation, and pure logic. It is, more or less, the desire to control and manage different areas of being such as spirit, society, organic, and inorganic nature represented by the methods of thinking and intuition, as well as the objectives of scientific thinking. Given that technology suppresses randomness of the individual who produces a work of art, it can be characterized as a good ally to a strictly defined scientific method. However, it does not lead the creation process, but serves the one who creates.

At the outset of this analysis it is necessary to start with extensive research of literature relevant to the certain methods (compare Sneed, 1978):

1. objective and function of proof in each discipline

2. detection and collection of evidences

3. evaluation of evidence to the authenticity and reliability

4. analysis and interpretation of the evidence

5. connection of beliefs supported by the evidence.

The purpose of this study is limited to a broad overview and comparison of different methods, and an attempt was not made to use specific techniques in each discipline produced or substantiated with evidences. Instead, the essence of this study is to provide information that can produce innovative thinking, increased perception and further research of any procedures that might seem to provide better answers or useful perspectives related to the problems confronted by various disciplines in their review (doing so with verification and use of evidences). Links are investigated and comparisons are made between the methods and techniques of the areas to be examined. Collection of methods, thus, means verification and analysis of evidences as primary need for successful implementation of their function in the process of scientific research.

Understanding methods and understanding people (events) are two different processes. Lecturer is in a position to upgrade the existing knowledge with facts, and in some cases to significantly alter the content of the subject which is dealt with, including changing the methods that will be used during the research. Different interpretation could be affected by new theories that have changed through several periods (Popper, 1973). The study of teaching method assumes its comparison with methods from different areas of research and identification of their differences that will help to determine the method itself. The teaching method at art academies requires a variety of images, ideas, perspectives and interpretations. 


\section{Teaching method: definition of principles}

In order to solve this problem, it is necessary to determine which aspect is more important - the course content teaching or teaching method. The choiceis difficult since both are important and inextricably intertwined. In order for someone to become a good teacher, mastery of both is essential. The teaching method is a means of transferring subject's content to students. However, reflection and attention to details is crucial in the process of selecting and using proper teaching methods. The success of the lecturers at the Art Academy depends on their creative endeavors, the spirit of testing and research, and the harmonization of relations between three invariants student, lecturer, and subject's content knowledge. All this should be achieved by using teaching methods. Teaching methods can be divided into three (compare Westwood, 2008):

\section{1. lecturer's methods \\ 2. interactive methods \\ 3. problem solving methods. \\ 1. Lecturer's methods}

In this method professor of the Faculty of Fine or Applied Arts selects, organizes and presents subject content to students. There are different variants of these methods. History of teaching method goes back to the time when there was no printing. Knowledge was communicated orally to pupil by teacher. The teacher used memory and orally transmitted knowledge to his pupils. In fact, the teaching method in the past was essential for the transfer of knowledge from generation to generation. ${ }^{4}$ The main characteristic of formal lecture is an exchange or communication - from lecturer to student. He makes all the decisions and teaches according to his predetermined plan. In this method, students are passive listeners. If they have any questions, they can ask at the end of the lecture. An informal lecture is an exchange of communication, however, here lecturer does not only depend on his predetermined plan, but also adds spontaneously subject content, depending on how the situation is developed. Students can participate in the discussion of key points, but the discussion is controlled by lecturer, as he chooses. With the aim to make a proper assessment of learning, lecturer should remember that learning involves student's full knowledge, therefore it is necessary to evaluate not only the cognitive development that affect lecturers, but also conative and affective development.

Cognitive development refers to thinking, training and learning, conative to selfdiscipline, cooperation, and creativity, and affective to concentration, enthusiasm and perception. A good lecturer understands cyclical nature of knowledge if he applies all three aspects: cognitive, conative and affective. If we want to achieve a certain degree of improvement in education, we need to offer a curriculum that meets not only the needs of basic subjects, but needs at every level. The lecturer should not only know the content of his subject, but conduct researches of curriculum.

\section{Interactive methods}

These methods are based primarily on the successful interaction between lecturer and students, as well as mutual interaction among students. The quality of teaching will be good if all parts of the whole are functional and the process starts from students and lecturer. The final results will be compromised if all students do not participate and give hundred percent in that interaction.

\footnotetext{
${ }^{4}$ In ancient Greece, specifically in Athens, citizens were too individualistic-minded. Although education was somehow mandatory for citizens, and the position could not be obtained without it, the state was nevertheless leaving every citizen the freedom to teach their sons. Ellwood P. Cubberley, The History Of Education, Kessinger Publishing, Whitefish, Montana, 2004, 23-36.
} 
However, it also depends on how much is important for a project that all students give their qualitative peak. A single class is a part of one wider educational system. Within that one part, all students should participate in interactive collaboration that will lead to the progress of that collective, but also an area that has been studied. Interactive collaboration can be undermined if the leader of the collective, that is, a lecturer, circumstantially is no longer able to lead certain collective. Deficiency may be especially noticeable if the lecturer used just those methods that led to the progress of individuals and established interactive collaboration can be affected by changing lecturer, and therefore the methods applied.

The results can be achieved even if one or more students do not invest their maximum in interactive collective collaboration. Eventhough, some students can individually achieve good results, full interactive cooperation may not be acomplished. In addition, a student who had previously exercised worse results and less successfully participated in interactive collaboration, may positevely affect the interactive cooperation. It is a fact that weaker student affect the results of tinteractive collaboration.

Therefore, it is very important fot the lecturer to pay attention to weaker students from the very beginning, identify their weaknesses in order to eliminate them and focusing on development of talents they possess. In this way, the interactive cooperation of the collective will be more successful. A good atmosphere can be established if all students and lecturer progress to a certain extent. At one point, the best results will be achieved and such a condition can delude the whole collective, starting with the lecturer. In that case, the collective results stagnate and even decrease. In the process of declining results the impact of individuals will be even more significant, which will affect the whole collective. In a situation when there is a decrease it is important to re-establish a qualitative interactive collaboration, which involves working with certain individuals who saw the process of qualitative decline.

If the qualitative falls occur simultaneously in multiple individuals in a short period of time, the consequences will soon be apparent. The occurrence of these falls in some individuals over a long period of time requires timely response so in the future those fall do not happen. Nevrtheless, divertig attention to an individual who achieves weaker results in interactive collaboration can affect performance of other individuals in the collective. This will happen because the redirection to a single individual or a few of them will cause neglection of otherother individuals and will open the possibility of achieving weaker results. However, neglection of weaker students will also adversely affect the work of the collective as well as individual results. It is very important to establish synergy during interactive cooperation as weaker student can learn from stronger ones and vice versa, thus the time may come when weaker students bring themselves to the level of other ones or even overcome them. At the same time, the complexity in terms of number of students, increases as from the largest part to the smallest groups. Therefore the detection of the smallest inaccuracy in more complex framework of the collective is harder (compare Kotarbiński, 1964).

At the beginning of the interactive collaboration and research lecturer exposes students plan of work, and then opens a direct discussion between students. Thus, it will be clear what kind of data is taken into consideration. Individual creativity involves mental efforts in the creation of ideas regarding the problem to be solved. However, at the beginning group creativity requires even greater efforts to accommodate individual creativity to collective. As the process develops, the individual mental efforts directed towards collective are evenly distributed giving the same qualitative results. At the same time, the lecturer extends and describes this process and gives different tasks to students. In collectives where art practice is conducted students need to understand the problem and propose solutions in order for the collective to move further in the process. It is quite understandable that in this area we must expect individuality and originality, but the task of lecturer through group action affects progress of each individual.

Thus, creativity influences the development of the group. Given that mental effort is in the service of a common task, it involves constant attempt to build and maintain a common 
understanding of the problem. That effort is maintained and it overcomes the multiplicity of potential incoherences and interruptions. While perfecting themselves, the students need to be able to develop ideas in a way that they have some sense for others and effectively implement them. Achievements of previous collectives should be taken in consideration since each new idea is built on the past. If we want to support creativity of the group, then we need to support the construction and continuation of joint space problem, a reference to the objects in this space, the collective memory of (relevant episodes in history) of the creativity (Sarmiento et al., 2008).

\section{Problem solving methods}

Problem that arises in lectures in art academies and culture in general is the existence of difference between art and science, because these two ways of action and thinking - artistic and scientific standpoint - are two very different worlds. Although the connection between art and science historically has often been relevant, example which was made by Leonardo da Vinci, an ideal which he represents is not a matter of agreement between the artistic and scientific community. Nevertheless, things are changing and new fields emerge from the synthesis of other areas. Leonardo's example shows how the boundary between science and art can be very thin, and that method should continue to be reviewed and brought into a new relationships with the events and development processes in the real world, be they from the past or present. ${ }^{5}$

The answer to the question of how to teach art practice and solve methods of fine art, presupposes the definition of ever-changing, because of cultural and historical reasons. The boundaries of art have experienced a radical change over the last century. Previously, art was created in historical confirmed medium and was presented in a limited set of content for a limited set of objectives, such as the search for beauty, religious glorification, or painting people and places. However, the previous century has produced new ways of experimenting, breaking and testing boundaries. Artists have introduced new mediums, contents, materials and purposes. Art education institutions have increasingly consumed different forms of experimentation. Modern artists use unconventional materials, tools, techniques and ideas, inspired by the world of science, technology, economics, psychology, sociology, anthropology, and so on. Some are present in nonartistic contents, such as factories, laboratories, internet, schools and street. Social interventions are numerous and the process of creating art is completed by problems related to the design and decision making. The standpoint of a design is associated with creative and innovative process while decision-making process rely on scientific approach in order to to solve a problem. In this sense, science can support art by providing materials, media, and rational approaches to problem solving. Lecturers at the art academies are guided by the curriculum, created under external influences, and syllabuses and materials used by their teachers. One of their tasks is to involve students in the learning process. Therefore, they try to make the best possible use of their knowledge and understanding of the subject to devise a model curriculum that meets the needs and interests of students. We call this comprehensive method of curriculum development.

\footnotetext{
5 Namely, in Milan after 1482, Leonardo came into contact with the German master, an expert in the construction of armor. Using the knowledge gained by dissection of corpses, he made mechanical models of muscles and joints. Leonardo's numerous projects, such as those of hand, confirm his complete understanding of the mechanisms of human and animal bodies. Da Vinci's initial impetus to develop robot technology probably came from his discovery of the ancient Greeks texts that have been translated by humanists. See more about this in: Mark Rosheim, Leonardo's Lost Robots, Springer, Berlin, Heidelberg, 2006.
} 


\section{How to improve teaching: teaching tools}

Teaching objectives determine teaching methods and teaching aids support them to make lectures more efficient, and thus enrich lectures. Types of teaching aids are (compare Forsyth et al., 1999):

1. printed materials

2. audio-visual materials.

\section{Printed materials}

Textbooks and scripts are the main source of printed materials. A number of lecturers at the Faculties of Fine and Applied Arts write scripts used for teaching and they are used as an efficient source:

a) the ideas for organizing the educational contents

b) activities, strategies and issues to help and improv teaching to suit student's learning needs

c) references, readings and other materials

d) plannning exercise on students' suggestions to think about ideas and informations given in the scripts and to use different parts of the text.

The lecturer should never limit his teaching by using only scripts as they contain the following weaknesses:

e) problem of the superficial use

f) small possibility of using critical thinking skills

g) script's aid is limited to perceptual aspect of cognitive development

h) does not encourage reasoning and creativity.

Additional material include encyclopedias, dictionaries, atlases, journals, magazines, newspapers and books. Lecturer proposes such additional material so that students are encouraged to explore ideas or themes as scientists. He asks students to describe such tasks in order to better understand these comparative materials.

\section{Audio-visual materials}

These materials send stimuli to several senses at the same time and they are effective in attracting students' attention. They include computer projectors that save a lot of time from the class that's very valuable. If the lecturer shows the movement of letters of words or symbol characters on the blackboard, it may not be seen by all students. If he shows them as transparent, all students can see exactly the movement of the hands and the right destination for placement of words, letters and symbols. This is better way than movies in the sense that the lecturer is working with students directly. It is very important to attract more attention from students in order to find out more about them. In doing so, everything that distracts their attention needs to be improved or eliminated from teaching. However, in winning the attention prominence of given stimulus is implicitly defined with respect to the other, only available to current stimuli. It is clear that elements attracting greater attention are clear, precise, and more interesting, therefore, the lecturer's task is to use those stimuli that have qualities other stimuli do not.

The stimuli are fixed longer in its irregular form and the heterogeneity of its elements distort the subject. Also, the stimuli are more easily identified if they appear in a new color. Events can affect our visual attention based on their individual visual structure, and they do so to the extent that surprises us if they violate our expectations. In doing so, at least part of conquered 
effect can be eliminated by some practice or use of predictable distractors. Conquest of attention is almost exclusively measured in terms of distraction, i.e. interference with the processing of information that is in progress (Hommel, 2002).

When it comes to movies, students have the opportunity to see events involving people, processes, and experiences that would not be able to see otherwise. ${ }^{6}$ Movies turn on eyes before ears, so they are comparatively more efficient. However, the lecturer, in the use of movie, has the ability to act in the following way (compare Marcus, 2010):

a) movies are directly related to the lecture

b) the lecturer watch the movie first, and it then his students

c) teaching objectives are communicated to students prior to the release of the movie, so they can watch the movie with this prior knowledge

d) the salient features of the movie are presented before watching

e) the lecturer asks students to write a brief description of the movie after watching

f) the lecturer determines the way of evaluation of the movie in order to verify its effectiveness.

\section{Conclusion}

The fact is that lectures at the Faculties of Fine and Applied Arts require methodological gradualism. Therefore, the study of theory and practice and consideration of the relationship between these two seemingly distant areas at these faculties require studious preparation and continuous study of the various problems that arise when synthesizing their knowledge and results. Therefore, the conclusion is that neither theory nor practice can not exist on their on. Theoretical knowledge is tested through lectures and exercises, and this is the first step in the process of learning through practice. During this process, the lecturer tries to introduce students first to theory, that is, he presents them a clearer basis of theoretical knowledge. All this is necessary in order for students to apply the knowledge obtained by listening and developing theoretical knowledge through lectures and exercises because it undoubtedly can help them later in their creative process. Technique is very important, although often the idea stands out as more important segment of an artist's creativity as without technique there is no realization of artistic idea. Therefore, the technique can be defined as one kind of form, which is a precursor to true form and also used for its display.

At the beginning, the process is chaotic, therefore, students' desire to find the right form is present. Also, there is aneed for a certain degree of freedom in this process so the process would not be builtd on the principle of automatism. Each structure follows the previous one because if there was no such order, inadequate form would be created. Therefore, appropriate form would one guided by hermeneutic principle of relations between the whole and its parts. In lectures at

\footnotetext{
${ }^{6}$ For example, one part of the film Dreams by Akira Kurosawa, entitled The Dream of Vincent Van Gogh, is a kind of dream, a fairy tale, which provides a new version of the discourse the 20th century as a paradigm of the 19th century and Van Gogh's work. Here is in the midst an journey through the intimate narrative woven by a fertile Eastern imagination, at the service of the artistic epic based on the clichés of the Van Gogh legend. The product of a dream, the story is consistent with the dreamlike experience that knows nothing of the perceptive boundary of human vision and the physical image. See Aurora Corominas, On Human Inside the Representation Space of the Paint Brush, Formats, Revista de Comunicació Audiovisual, 2005.
} 
art academies both traditional and modern mediums are used. That way, students's ability to respond to different types of challenges is stimulated, and at the same time they learn how to be flexible in recognizing diversities. Thus, they will have a clear idea of spiral development, which not only explains the methods in their historical development, but also different types of mediums that can help us verify the effectivness of applied teaching methods.

\section{References}

1. Corominas, A. (2005). On Human Inside the Representation Space of the Paint Brush. Formats, Revista de Comunicació Audiovisual.

2. Cubberley, E. P. (2004). The History Of Education. Whitefish, Montana: Kessinger Publishing.

3. Forsyth, I., Jolliffe, A. and Stevens, D. (1999). Delivering a Course: Practical Strategies for Teachers, Lecturers and Trainers. London: Routledge.

4. Hommel, B. (2002). What Grabs Us: Comment on Ruz and Lupianez. University of Leiden.

5. Kotarbinjski, T. (1964). Traktat o dobrom delanju. Beograd: Nolit.

6. Marcus, A. S. (2010). Teching History With Film: Strategies for Secondary Social Studies. London: Taylor and Francis Group.

7. Poper, K. (1973). Logika naučnog otkrića. Beograd: Nolit.

8. Rosheim, M. (2006). Leonardo's Lost Robots. Berlin, Heidelberg: Springer.

9. Sarmiento, J. W., Gerry, S. (2008). Group Creativity in Interaction: Collaborative Referencing, Remembering, and Bridging. Journal of Human-Computer Interaction, 24(5), 1-13.

10. Schökel, L. A. (1998). A Manual of Hermeneutics . Sheffield: Academic Press.

11. Sneed, F. R. (1978). Parallelism in Two Disciplines. Manchester, New Hampshire: Ayer Publishing.

12. Westwood, P. S. (2008). What Teachers Need to Know about Teaching Methods. Melbourne: Aust Council for Ed Research. 